\title{
El Galeón de Manila: mercancías, personas e ideas viajando a través del Pacífico (1565-1815)
}

\section{The Manila Galleon: Commodities, People and Ideas traveling across the Pacific (1565-1815)}

\author{
DOI: $10.32870 /$ mycp.v9i26.677
}

\author{
José Antonio Cervera Jiménez ${ }^{1}$
}

\begin{abstract}
Resumen
El Galeón de Manila, o Nao de China, constituyó la ruta transpacífica más importante entre los siglos XVI y XIX. La ciudad de Manila se convirtió en el lugar donde numerosas mercancías chinas y de otros países asiáticos eran intercambiadas por plata americana y donde se embarcaban rumbo a Acapulco, desde donde se distribuían después al resto de la América hispana y a Europa. El presente artículo aporta una visión panorámica de la historia de esta ruta transpacífica. Además de servir de estado del arte de las investigaciones que se han llevado a cabo acerca del tema, se realiza un enfoque integral al incluir, no sólo el tráfico de mercancías, en el que se ha centrado la mayoría de los autores, sino también los movimientos de personas e ideas, así como las regulaciones al comercio y la distribución entre los principales actores de las ganancias extraídas de este viaje transpacífico. El acento en el intercambio de textos e ideas entre ambos lados del Pacífico constituye uno de los puntos más novedosos de este artículo.
\end{abstract}

Palabras clave: Galeón de Manila, océano Pacífico, Nueva España, Filipinas, siglos XVI-XVIII

\begin{abstract}
The Manila Galleon, or Nao de China, was the most important transpacific route between the 16 th and the 19th centuries. The city of Manila became the place where commodities from China and other Asian countries were exchanged for American silver. These goods were loaded and sent to Acapulco, from where they were distributed to the rest of Hispanic America and Europe. This paper provides a panoramic vision of the history of this transpacific route. In addition to serving as a state of the art of the current research about this topic, a comprehensive approach is carried out by including not only the traffic of goods, which most authors have focused on, but also the movements of people and ideas, as well as the regulations for trade and distribution among the main actors of the profits extracted from this transpacific journey. The exchange of texts and ideas between both sides of the Pacific Ocean is emphasized in this paper.
\end{abstract}

Keywords: Manila Galleon, Pacific Ocean, New Spain, Philippines, $16^{\text {th }}-18^{\text {th }}$ centuries

Artículo recibido el 17 de noviembre de 2019 y dictaminado el 24 de enero de 2020.

1. El Colegio de México, Centro de Estudios de Asia y África. Carretera Picacho Ajusco, 20, Col. Ampliación Fuentes del Pedregal, Tlalpan, Ciudad de México, México. C.P. 14110. ORCID: https:// orcid.org/0000-0001-6972-3897 . Correo electrónico: jacervera@colmex.mx 


\section{Introducción}

Durante dos siglos y medio, la ruta del Galeón de Manila o Nao de China constituyó un puente entre los continentes asiático y americano. México quedó "en el centro del mundo", ${ }^{2}$ al situarse el virreinato novohispano en una posición clave entre Europa y Asia. Este texto pretende ser un breve relato sobre el establecimiento de esta ruta transoceánica, así como de su papel para el intercambio de mercancías, personas e ideas, como expone el título, entre ambas orillas del Pacífico.

El reino de Castilla buscó la ruta a Asia cruzando el océano Atlántico desde la época de los Reyes Católicos. A pesar de la llegada al nuevo continente americano, los españoles no dejaron de soñar con llegar a las ricas tierras del mítico Cathay, así como a las islas de la Especiería -como se conoció a las Molucas-, de donde provenían las especias más preciadas en los mercados europeos. Durante el siglo XVI hubo varias expediciones castellanas a Asia Oriental. Las dos primeras partieron de España (la protagonizada por Fernando de Magallanes y Juan Sebastián Elcano, que partió de Sanlúcar de Barrameda en septiembre de 1519 y llegó a Filipinas en 1521; y la dirigida por García Jofre de Loaisa, que partió de La Coruña en julio de 1525 y llegó a Filipinas y las Molucas a finales de 1526). Las siguientes expediciones (dirigidas por Álvaro Saavedra Cerón, 1527; Hernando Grijalva, 1537; y Ruy López de Villalobos, 1542) partirían ya desde el virreinato de la Nueva España. Sería la expedición comandada por Miguel López de Legazpi, que partió del puerto de la Navidad en noviembre de 1564, la que llegaría a establecer un asentamiento español permanente en el archipiélago filipino, concretamente en Cebú, en abril de 1565. El nieto de Legazpi, Felipe de Salcedo, junto con el fraile agustino Andrés de Urdaneta, consiguieron encontrar el tornaviaje o ruta de navegación de Filipinas a Nueva España. El derrotero que siguieron se dirigió primero hacia el norte, bordeando Japón. A unos 38 o 40 grados de latitud Norte, entraron en la corriente de Kuroshivo, que los llevó en dirección Este hasta la costa americana a la altura de California, para ir costeando después hacia el Sur hasta llegar al puerto de

2. A principios del siglo XVII, Bernardo de Balbuena se refería a México en su poema Grandeza Mexicana de la siguiente forma: "en ti se junta España con la China, / Italia con Japón y, finalmente, / un mundo entero en trato y disciplina; // en ti de los tesoros del poniente / se goza lo mejor; en ti, la nata / de cuanto entre su luz cría el oriente" (Balbuena, 1604/2014, p. 223). 
Acapulco. De esta forma, inauguraron la ruta de ida y vuelta entre América y Asia que cruzaría el Pacífico durante los siguientes siglos. ${ }^{3}$

Durante los primeros años de presencia española en las Filipinas, este archipiélago era considerado como una especie de "trampolín" hacia un objetivo mejor. Desde el principio se ambicionaban las Molucas, las islas de las especias donde los portugueses estaban establecidos desde 1512 y adonde habían llegado varias de las expediciones castellanas del siglo XVI. Sin embargo, los españoles también tenían puestos los ojos en el gran Imperio chino. Tras un lustro de indefinición, ${ }^{4}$ los españoles del archipiélago optaron por este gran país asiático. El centro neurálgico pasó en 1571 de Cebú a Manila, situada estratégicamente en la costa oeste de Luzón, cerca de la costa china. Desde ese momento, la capital filipina se convertiría en el lugar de encuentro o puente entre la Nueva España y el Imperio de la dinastía Ming. ${ }^{5}$

Legazpi, en su camino hacia Manila, encontró a varios chinos cautivos y los liberó. Varios de esos cautivos volvieron a su tierra y, posteriormente, fueron a Manila a vender sus productos. ${ }^{6} \mathrm{El}$ comercio entre españoles y chinos creció en las últimas décadas del siglo XVI y las primeras del XVII hasta límites insospechados. Nacía, así, la ruta del Galeón de Manila-Acapulco o Nao de China.?

3. La historia de las expediciones hispanas a Asia Oriental del siglo XVI, así como el viaje de LegazpiUrdaneta, ha sido suficientemente estudiada por los investigadores. Destacan, entre otros, los libros de Gil (1989), Bernabéu (1992), Molina (1992), Rumeu de Armas (1992), Hidalgo (1995), así como dos obras colectivas, que contienen la aportación de numerosos investigadores filipinólogos que se dedican actualmente a este tema: Truchuelo (2009) y Barrón (2012).

4. Esa indefinición aparece explícitamente en una carta de Legazpi, escrita en julio de 1570, donde el "Adelantado" y primer gobernador de las Filipinas pregunta al virrey de la Nueva España si debe permanecer en Cebú, en el caso de que se pretenda llegar a las Molucas, o bien establecerse en Manila, si lo que se quiere es llegar a la costa china. La carta se encuentra en el Archivo General de Indias (Patronato, 24), y está reproducida en: http://www.upf.edu/asia/projectes/che/s16/ lega1570.htm

5. El traslado de la "capital" filipina de Cebú a Manila indica que prevalecieron las pretensiones sobre China, en lugar de la conquista de las islas de la Especiería. Este hecho, fundamental para la posterior historia de Filipinas, hoy es aceptado por la mayor parte de los investigadores, tales como Ollé (2002, p. 46), Folch (2008, p. 45) y Sánchez (2009, p. 624).

6. Este episodio es relatado por el propio Legazpi en una carta dirigida al virrey novohispano y fechada en Manila el 11 de agosto de 1572 (AGI, Patronato, 24, reproducida en: http://www.upf.edu/asia/ projectes/che/s16/lega1572.htm).

7. Dos obras colectivas recientes que estudian el Galeón de Manila, sobre todo desde el punto de vista económico y cultural, son la de Bernabéu (2013) y la de Bernabéu y Martínez Shaw (2013). 


\section{Los primeros misioneros en Filipinas y los chinos del Parián de Manila: ideas viajando por el Pacífico}

Entre los primeros españoles que llegaron a Filipinas destacan algunos misioneros de órdenes religiosas católicas que intentaron, y en gran parte consiguieron, tener un contacto fluido con los naturales del país y también con los sangleyes, término con el que se conocía a los chinos en el archipiélago filipino. Desde el principio, el mayor anhelo de esos misioneros fue precisamente introducirse en la China de la dinastía Ming y establecer una misión permanente en el Imperio. ${ }^{8}$

La primera orden que se estableció en las islas fue la de San Agustín. Además de Andrés de Urdaneta (1508-1568), ya nombrado anteriormente por su papel en el "descubrimiento" del tornaviaje, junto con Legazpi llegaron cuatro agustinos, de los cuales el más destacado fue Martín de Rada (15331578)..$^{9}$ Además de haber sido un gran matemático y astrónomo, Rada fue también uno de los primeros españoles que visitaron el Imperio chino, en 1575, enviado en viaje oficial en representación de las autoridades españolas de Manila. ${ }^{10}$ Tras su viaje, escribió una crónica o Relación que sería importante para el conocimiento de China en la Europa de su tiempo. Éste es uno de los primeros ejemplos de circulación de ideas, en este caso, de carácter tanto cultural como científico, a través del Pacífico. Según Henri Bernard, el viaje de Rada constituye la primera exploración científica de China hecha por un europeo (1933, p. 108). La Relación de Rada, junto con la Relación de Loarca, son dos de los primeros textos que hicieron conocer a los europeos la geografía, la historia, la cultura y las costumbres del Imperio chino. ${ }^{11} \mathrm{Y}$ esos textos no llegaron a Europa por la ruta del Índico y África, sino cruzando los océanos Pacífico y Atlántico.

8. Dos libros que dan una buena información general sobre la historia de la Iglesia en Filipinas y el papel que jugaron las órdenes religiosas en la evangelización y en la vida cultural, educativa y social del archipiélago, son los de Gutiérrez (1992) y Moffett (2005).

9. Una obra que reúne buena parte de los documentos originales relacionados con Urdaneta y Rada es la compilación de Rodríguez (1978, vols. 13 y 14).

10. Para la vida y obra de Rada, véanse Folch (2008) y Cervera (2013, pp. 136-203).

11. Miguel de Loarca fue uno de los soldados que acompañó a Rada en su viaje a China. Igual que Rada, escribió una Relación sobre ese viaje que sería utilizada por el agustino Juan González de Mendoza (1545-1618) para escribir su libro Historia del Gran Reino de la China, publicado por primera vez en 1585. La obra de Mendoza sería traducida a varios idiomas antes de 1600 y se convertiría en la principal fuente de conocimiento sobre China en la Europa de su época. Para un estudio sobre la Historia del Gran Reino de la China, véase Sola (2016). 
Tras los agustinos, los siguientes en llegar fueron los franciscanos, en 1578. También ellos intentaron desde el principio dar el salto a China. El superior de la misión, Pedro de Alfaro (?-1580), protagonizó el primero de varios intentos, siempre frustrados, de esta orden religiosa para introducirse en el Imperio chino desde Manila. ${ }^{12}$ En 1581 llegarían los primeros jesuitas. Junto con ellos arribó el primer obispo de Manila, el dominico Domingo de Salazar (1512-1594), aunque el primer grupo de miembros de la Orden de Santo Domingo llegaría en $1587 .{ }^{13}$ Los dominicos fueron los primeros que se marcaron el objetivo de evangelizar a la numerosa comunidad de los sangleyes de Manila. Para poder llevarlo a cabo, tuvieron que aprender la lengua china. El más destacado fue Juan Cobo (?-1592), pionero en traducir la primera obra china al español y escribir en chino una obra religiosa con alto contenido filosófico y científico, adelantándose a lo que años después harían los jesuitas. ${ }^{14}$ Cobo fue enviado por el gobernador de Filipinas ante el kampaku (o regente) de Japón, Toyotomi Hideyoshi, que había enviado una misiva pidiendo tributos a los españoles con la amenaza de invasión. Tras su misión diplomática, Cobo murió en el viaje de vuelta a Filipinas.

No se puede explicar la ruta de la Nao de China sin hacer referencia a la nutrida comunidad de los chinos de Manila. Precisamente las mejores crónicas del Parián, el barrio donde vivían los sangleyes, fueron hechas por algunos de los dominicos que trabajaron con ellos en el siglo XVI. Juan Cobo escribió una carta a sus compañeros de orden de Chiapas y Guatemala, fechada el 13 de julio de 1589, que fue publicada poco después por Antonio de Remesal (1619). En esa carta, Cobo dice de los chinos de Manila:

Ellos tienen aqui en Manila junto al rio vn Mercado que llaman Pariàn, que es vna grande quadra de portales, en medio de los quales quatro paños esta vna balsa de agua grande con vna puente al rio, por donde entra y sale el agua, aqui

12. Para la historia de la llegada de los franciscanos a Filipinas, véanse Sánchez y Fuertes (1979) y Morales (2008).

13. La mejor obra para conocer la llegada de los dominicos a Filipinas es la crónica de uno de los primeros miembros de la orden en el archipiélago, Diego Aduarte (1640/1962).

14. Me refiero al Bian Zhengjiao Zhenchuan Shilu 辨正教真傳實錄, que se podría traducir como Auténtico registro de la discusión de la verdadera propagación de la Religión Ortodoxa. Esta obra, una de las primeras impresas en Filipinas, es el segundo libro escrito en chino por un europeo y constituye la primera obra en ese idioma que introduce el cristianismo desde un punto de vista racional, y también el primer libro en chino con ideas científicas occidentales. Hay una edición moderna del Shilu, con traducción al español y al inglés (Villarroel, 1986). Para un estudio en profundidad de esta obra de Cobo, véase Cervera (2013, pp. 393-481). 
entran con sus barquillos y con sus champanes, que son como varcos pequeños, y con sus bancas, que son vnos nauichuelos de ancho como vna vara de medir, y de largo de ocho y diez varas, son sin cuento los que entran y salen. En este Mercado ay mercaderias de seda, de lienço, de quantas cosas quieren los hombres. Ay oficiales de quantos oficios quisieren, plateros, sastres, çapateros, carpinteros, pintores cereros, \&c. (...) Finalmente quantos oficios quisieren tantos ay. (Juan Cobo, 1589, reproducido en: Remesal, 1619, p. 681).

También Domingo de Salazar, el primer obispo de Manila, escribió una Cartarelación de las cosas de la China y de los chinos del Parián de Manila dirigida al rey Felipe II, fechada en Manila el 24 de junio de 1590, en la que se puede leer:

Ay en este Parián médicos y boticarios, con rétulos en sus lenguas puestos en las boticas, que declaran lo que en ellas se bende; ay también bodegones en mucha cantidad, donde acuden los sangleyes y naturales á comer, donde me diçen que también acuden spañoles; los officios mecánicos de los Españoles an cessado todos, porque todos se visten y calçan con sangleyes, por ser muy buenos oficiales, al uso de España, y háçenlo todo muy barato; (...) Lo que acá á todos nos á caydo en mucha graçia es que vino aquí un enquadernador de México, con libros, y puso tienda para enquadernar; asentó con un sangley, diçiendo que le quería servir, y, disimuladamente, sin que el amo lo hechase de ver, miró cómo enquadernava, y en menos de ... se salió de su casa diçiendo que ya no le quería servir, y puso tienda deste oficio; y certifico á Vuestra Magestad que salió tan exçelente oficial, que al maestro le á sido forçoso dexar el oficio, porque todos acuden al sangley, y haçe tan buena obra, que no haçe falta el oficial Español; (...) Ay muchos ortelanos entre estos sangleyes, que en partes donde parescía no poderse dar nada, crían ellos muy mucha y muy buena ortaliça ansí de la de España como de la de México, y tienen esta plaça tan proveída como la de Madrid ó Salamanca. Haçen sillas, y frenos, y estribos, tan buenos y tan varatos, que algunos mercaderes quieren de ellos haçer cargaçón para México. (Domingo de Salazar, 1590, reproducido en: Retana, 1897, pp. 65-67).

Las anteriores descripciones del Parián de Manila indican de manera vívida que este lugar constituía el punto central de la ruta entre Nueva España y China. ${ }^{15}$ Algunas referencias, tales como los fragmentos que indican que "los oficios mecánicos de los españoles han cesado todos, porque todos se visten y calzan con sangleyes, (...) y lo hacen todo muy barato", y que "hacen sillas, y

15. La transcripción de las dos Cartas-relaciones citadas anteriormente (la de Cobo de 1589 y la de Salazar de 1590), así como su análisis, forman el núcleo del libro de Cervera (2015). 
frenos, y estribos, tan buenos y tan baratos, que algunos mercaderes quieren de ellos hacer carga para México", por no hablar del caso del encuadernador de libros chino que aprendió el oficio y "salió tan excelente oficial, que al maestro le ha sido forzoso dejar el oficio, porque todos acuden al sangley", muestran que en el siglo XVI existían prácticas y pautas de comportamiento que no nos son extrañas en nuestro siglo XXI.

Personajes como Rada, Salazar y Cobo inauguraron dos siglos y medio durante los cuales las ideas europeas cruzaron el Pacífico y modelaron la realidad de países como Filipinas e influyeron en otros como China y Japón. Pero esa transferencia de ideas, de cultura, de ciencia, no se dio solamente en dirección a Asia. Los textos anteriormente citados son sólo un ejemplo de los cientos que cruzaron el océano desde Manila hacia Acapulco y que influyeron tanto en el virreinato novohispano como en Europa. Crónicas religiosas y seculares, cartas y relaciones, dieron a conocer China y otros países asiáticos a autoridades, a hombres de Iglesia y a intelectuales de los países de la América española y también europeos, llegando a desarrollarse una visión profundamente positiva de países como China. ${ }^{16}$

Los textos llegados al virreinato novohispano desde Asia incluso colocaron a México en el centro de algunas polémicas que se habían gestado en el otro extremo del mundo. Uno de los ejemplos más claros tuvo como protagonista al famoso obispo de Puebla y virrey Juan de Palafox y Mendoza (1600-1659), uno de los personajes más destacados del siglo XVII novohispano. Hay que recordar que la Capitanía General de Filipinas formaba parte del virreinato de Nueva España, y también que los miembros de las órdenes religiosas con presencia en Filipinas y otros países de la región estaban muy vinculados con el clero afincado en México. Por eso, a pesar de la gran magnitud del océano Pacífico, la Iglesia novohispana había desarrollado lazos estrechos con Asia Oriental. Sintiéndose responsable en cierto modo de la evangelización de China, el obispo Palafox tuvo un papel destacado en la Controversia de los Ritos

16. Véase, por ejemplo, la obra editada por Vega (2009), donde se recogen varias crónicas de viajes a China realizadas por españoles y portugueses durante el siglo XVI, las cuales se difundieron rápidamente por toda Europa. 
Chinos, que tanto influiría en el destino del cristianismo en el país asiático durante los siglos XVII y XVIII. ${ }^{17}$

\section{Viajando de Acapulco a Manila: la plata y otros productos}

Estrictamente hablando, el origen de la ruta del Galeón de Manila no estuvo en la compra de mercancías chinas. Los primeros productos que cruzaron el océano de Asia a América tenían origen filipino. Los pueblos o doctrinas en que se concentró a los indígenas filipinos, sucesores de los tradicionales barangays, ayudaron al principio a desarrollar la agricultura y a que hubiera un excedente, que alimentó al galeón que iba a Acapulco. Sin embargo, como señala Luis Alonso, la legislación impuesta por los españoles en Filipinas en materia tributaria condujo a la inflación y a la disminución de la actividad agrícola y, a raíz de ello, a una carestía y al sobreprecio de los productos filipinos en el mercado de Acapulco; esto no ocurrió con los productos chinos, que, al mantenerse más baratos, finalmente desplazaron a las mercancías filipinas en el comercio con la Nueva España (2009, p. 44). La economía filipina quedó, así, subordinada a mantener una agricultura para alimentar a la población local y a proveer de servicios al entorno del galeón, y los bienes que se comercializaban y se enviaban a Acapulco empezaron a tener un origen principalmente chino. El número de sangleyes residentes en Manila aumentó en pocos años de manera extraordinaria. Para finales del siglo XVI y principios del XVII, una población flotante de entre veinte mil y treinta mil chinos abarrotaba el Parián y otros barrios de la capital filipina.

Para poder entender este aumento de la población china, hay que tener en cuenta la situación histórica que vivía su país. La dinastía Ming, gobernante en China, había mantenido una actitud de aislamiento hacia el exterior, al establecer, entre otras medidas, una política de haijin 海禁, literalmente, "prohibición del mar". Sin embargo, debido a las presiones de los comerciantes locales, en 1567 se aprobó para Fujian una apertura marítima parcial que per-

17. La Controversia de los Ritos Chinos, que enfrentó a los jesuitas con los miembros de las órdenes mendicantes, ocurrió durante buena parte del siglo XVII y principios del XVIII. Tras fuertes enfrentamientos teológicos e incluso personales que tuvieron lugar en China y en Europa, la Santa Sede al final dio la razón a los dominicos y franciscanos en su interpretación de los ritos chinos, y esto llevó a la ruina a la misión católica en el Imperio chino. Un libro que abarca toda la historia de la controversia es el de Minamiki (1985). El papel del obispo Palafox y Mendoza en esta controversia se expone en el reciente artículo de Cervera y Martínez (2018). 
mitía la salida de juncos chinos. Se expidieron permisos para que un número determinado de barcos pudiera dirigirse a los puertos del sudeste asiático. Además, muchas otras naves viajaban sin permiso oficial (Ollé, 2006, p. 33). En definitiva, la llegada de los españoles a Manila coincidió con un momento de gran efervescencia del comercio marítimo chino, y eso posibilitó la llegada a la capital filipina de gran cantidad de juncos procedentes de Fujian.

Por otra parte, la plata tenía mucha importancia en China, lo que también coincidió con el reciente descubrimiento de ricas minas de ese metal precioso en los virreinatos de la Nueva España y del Perú. Durante la dinastía Ming, los distintos tipos de impuestos en China, que al principio se pagaban en grano y seda, se unificaron en un solo tipo de tributo que se tenía que pagar en plata (Botton, 2000, p. 307). Esto provocó una enorme demanda de ese metal. China empezó a ser el destino de las grandes fuentes de plata mundial de la época: Rusia, Japón y la América española. Este metal era tan apreciado en China, que su cambio con respecto al oro era bastante mayor que en Europa. La venta de plata a los chinos, por tanto, se convirtió en un negocio en extremo redituable. Además, desde el primer momento, los castellanos fueron conscientes de que lo único que podían ofrecer a China a cambio de sus ricas mercancías era plata. El virrey novohispano, Martín Enríquez, escribía a Felipe II una carta en diciembre de 1573 donde hablaba acerca del incipiente comercio con los chinos, de la siguiente forma:

...vna de las difficultades queste trato y comerçio tiene es que desta tierra ni despaña, asta lo que agora sentiende, no se les puede lleuar nada, que ellos no tengan, porque tienen abundancia de sedas y lençería: dizen asimismo que la tienen; paños, por ser la tierra caliente, no los gastan ni los tienen en nada; açúcar, ay gran abundançia; çera y drogas y algodón en las islas ay gran cantidad, a donde ellos lo uienen a rrescatar. Por manera que se viene a resumir que la contrataçión desta tierra á de ser con plata, que es lo que ellos más estiman. (AHN, Archivo Histórico Nacional de España, Doc. Ind., Secc. Div., n. 219, reproducido en: http://www.upf.edu/asia/projectes/che/s16/virr1573.htm).

Normalmente, la plata circulaba en China por peso. No existía la uniformidad monetaria; la determinación del peso y la pureza la hacían cada casa de cambio. Por ese motivo, el real de a ocho novohispano, debido a su estabilidad 
y pureza, fue muy apreciado en China, y posibilitó el intercambio entre los comerciantes europeos y chinos. ${ }^{18}$

La plata era el producto más importante que se transportaba desde Acapulco a Manila, y con ella se pagaban las mercancías chinas. Pero en su viaje hacia Asia, el galeón también llevaba gran variedad de productos, tanto europeos como novohispanos, tales como cacao, vainilla, tintes o cueros (Del Castillo, 2012, p. 138). Es especialmente relevante la introducción al Imperio chino de cultivos agrícolas de origen americano, tales como la papa, el maíz, el tabaco, el cacahuate, el girasol, el tomate o la calabaza (Zhang, 2003, p. 115). Algunos de esos productos ayudaron a la mejor alimentación de la población del país y posibilitaron un aumento de población sin precedentes durante la dinastía Qing, momento en el que China llegó a los 400 millones de habitantes.

El Galeón de Manila también constituía el modo como llegaban a Filipinas los migrantes desde la Nueva España, entre los que estaban las autoridades, los comerciantes, los religiosos, así como los soldados y los reos. ${ }^{19} \mathrm{El}$ número de personas que podía transportar normalmente un galeón se situaba aproximadamente entre las 300 y las 400 (Cabrero, 2009, p. 571).

\section{Viajando de Manila a Acapulco: mercancías y migrantes asiáticos}

Desde nuestra perspectiva mexicana, estamos acostumbrados a considerar a Acapulco como el inicio de la ruta. Sin embargo, en realidad, los galeones partían de Manila o, más estrictamente hablando, de Cavite. Era en el puerto de Cavite, a pocos kilómetros de Manila, donde se construían y se reparaban los barcos. Cavite tenía tres características que hicieron que los barcos de la ruta del galeón se construyeran allí: se consideraba un puerto seguro, en las cercanías había abundante y excelente madera (a diferencia de las costas novohispanas, donde los árboles no eran tan buenos para la construcción de barcos), y también podía ofrecer la mano de obra necesaria (Cabrero, 2009, p. 566).

Ya antes se ha hablado del Parián de Manila, lugar donde se realizaba el contacto entre chinos y españoles y donde la plata americana era intercambiada por mercancías. Los productos, provenientes de toda Asia Oriental y

18. Un excelente estudio de la historia de la plata novohispana en Asia Oriental es el de Valdés (1987).

19. García de los Arcos (1996) ha estudiado la emigración de mexicanos a Filipinas durante la época virreinal. 
Meridional, en especial de China, eran de una enorme variedad. Un texto de la época, el famoso libro de Antonio de Morga Sucesos de las Islas Filipinas, es suficientemente explícito:

De ordinario, vienen de la gran China á Manila, mucha cantidad de somas y juncos (que son navíos grandes), cargados de mercaderías, (...) y las que comunmente traen y se venden á los Españoles, son seda cruda en mazo, fina de dos cabezas, y otra de menos ley; sedas flojas finas, blancas y de todos colores, en madejuelas, muchos terciopelos llanos, y labrados de todas labores, colores y hechuras; y otros, los fondos de oro, y perfilados de lo mismo; telas y brocadetes de oro y plata, sobre seda en diversas colores y labores, mucho oro y plata hilada en madejas, sobre hilo y sobre seda, pero, la hojuela de todo el oro y plata, es falsa, sobre papel: damascos, rasos, tafetanes, y gorbaranes, picotes, y otras telas de todas colores, unas mas finas y mejores que otras; cantidad de lenceria de yerba, que llaman lenzesuelo, y de mantería blanca de algodon, de diferentes géneros y suertes; para todo servicio; almizcle, menjuy, marfíl, muchas curiosidades de camas, pabellones, sobrecamas y colgaduras, bordadas sobre terciopelo; damasco y gorbaran de matices, sobremesas, almohadas, alfombras, jaezes de caballos de lo mismo, y de abalorio y aljofar; algunas perlas y rubies y zafiros, y piedras de cristal vacías, peroles, y otros vasos de cobre, y de hierro colado; mucha clavazon de toda suerte, fierro en plancha, estaño y plomo, salitre y pólvora, harina de trigo, conservas de naranja, durazno, escorzonera, pera, nuez moscada, jenjibre, y otras fructas de la China, perniles de tocino, y otras cecinas, gallinas vivas, de casta, y capones muy hermosos, mucha fruta verde, de naranjas de todos géneros, castañas muy buenas, nueces, peras, y chicueyes, verdes y pasados, que es fruta muy regalada; mucho hilo delgado, de todo género, agujas, antojos, cajuelas, y escritorios, y camas, mesas, y sillas y bancos, dorados, y jaspeados de muchas figuras, y labores, búfalos mansos, gansos como cisnes, caballos, algunas mulas y jumentos, hasta pájaros enjaulados que algunos hablan, y otros cantan, y los hacen hacer mil juguetes; otras mil bujerías y brincos de poca costa y precio, que entre los Españoles son de estima, sin mucha loza, fina de todas suertes, canganes, y sines, y mantas negras y azules, y tacley, que es abalorio de todo género, y cornerinas ensartadas, y otras cuentas y piedras de todas colores, pimienta y otras especias y curiosidades, que referirlas todas, sería nunca acabar, ni bastaría mucho papel para ello (Morga, 1609/1890, pp. 351-352).

Buena parte de esas mercancías se enviaba en el Galeón de Manila hacia la Nueva España. Entre los productos que cruzaban el Pacífico, había telas de todo tipo, especialmente de seda, también especias, por ejemplo, canela y, 
por supuesto, porcelanas y otras artesanías: espejos, muebles lacados, tibores, etcétera (Valdés, 1987, p. 86).

Hay que señalar, sin embargo, que el tipo de mercancías transportadas y su origen fueron cambiando a lo largo de los siglos. Si en las primeras décadas de existencia de la ruta transpacífica, la mayoría de los productos procedía de China, al final del periodo, ya en el siglo XVIII y principios del XIX, entre el puerto filipino y el novohispano se transportaban mercancías procedentes de la India con un valor similar al de las que procedían de China (Legarda, 2009, p. 605). Probablemente este hecho esté relacionado con que, si bien durante el primer siglo de existencia de la ruta, como ha sido dicho, los que llevaban las mercancías a Manila eran principalmente chinos, a partir de finales del siglo XVII, muchos comerciantes europeos llegaron a la capital filipina para beneficiarse del comercio de mercaderías asiáticas. Eran principalmente ingleses y holandeses, aunque también había franceses, portugueses, suecos y daneses (Yuste, 2012, p. 210).

También hubo un gran número de personas que cruzaron el océano. Según Edward Slack, en los dos siglos y medio que duró la ruta del Galeón de Manila, un mínimo de 40 mil a 60 mil asiáticos llegó a Acapulco, siendo el doble (unos cien mil) una cifra probable, la mayoría de los cuales se distribuyó, o en la costa del Pacífico, en lo que hoy son los estados mexicanos de Jalisco, Michoacán y Guerrero, o en las ciudades de México, Puebla y Veracruz (2012, p. 99). Otros autores, como José Luis Chong, matizan un poco ese número, pues argumentan que no pudieron llegar tantas decenas de miles de asiáticos a la Nueva España, debido simplemente a la capacidad de personas que podían transportar los galeones y al número de éstos que navegó realmente. Chong establece el número de asiáticos que pudieron realizar el viaje hasta América en unos catorce mil como máximo (2013, p. 233).

La experiencia de las personas procedentes de China, India y otros países en la Nueva España fue muy diversa. Recientemente se han publicado algunos estudios sobre esclavos asiáticos en el país. ${ }^{20}$ Pero, al mismo tiempo, muchos asiáticos en el virreinato se integraron bien en el medio que les tocó vivir y

20. Véanse, por ejemplo, las obras de Oropeza (2011) y Seijas (2014). 
llegaron a tener una posición social importante. ${ }^{21}$ De cualquier forma, está claro que la influencia asiática en la Nueva España fue enorme, llegando a transformar culturalmente al país que hoy es México, hecho que no ha sido suficientemente estudiado hasta la fecha.

\section{Regulaciones de la ruta transpacífica}

A pesar de que entre Filipinas y México hay miles de kilómetros, el archipiélago siempre dependió de su contacto con la Nueva España durante la época de la ruta transpacífica. Este comercio, que supuso grandes beneficios a los comerciantes particulares involucrados, también dio buenos dividendos para la Real Hacienda, a partir de diversos tipos de impuestos (más de cien mil pesos anuales, según Vera Valdés, 2012, p. 182). Sin embargo, muy pronto se vio la necesidad de devolver parte de ese dinero a Manila. En 1606 se instituyó el situado, dinero procedente de los derechos fiscales cobrados en Acapulco y que se utilizaba para financiar las instituciones coloniales del archipiélago. El situado suponía el retorno de los impuestos cobrados en Acapulco por las mercancías chinas enviadas desde Manila. Es decir, en lugar de llegar a las arcas reales en México o en Madrid, parte del dinero que la Real Hacienda obtenía del comercio del galeón volvía a las Filipinas para sostener a la colonia. De esta manera, el archipiélago filipino dependía económicamente del virreinato novohispano.

Este hecho ha llevado a considerar que las Filipinas fueron deficitarias durante toda la época virreinal. Al menos, así lo señalaba hace unas décadas Pierre Chaunu en uno de los estudios más influyentes sobre la economía filipina durante los siglos XVI, XVII y XVIII (1974, p. 263). Sin embargo, recientemente, Luis Alonso ha demostrado que la idea de una Hacienda filipina deficitaria es ficticia. Si al estudio de Chaunu (realizado según los datos de la Hacienda central filipina) se le añaden las cuentas de las Haciendas provinciales, como ha hecho Alonso, se ve con claridad que las Filipinas no supusieron una carga para las arcas reales, como tradicionalmente se ha señalado (2009, p. 166).

21. Un caso paradigmático es el de dos japoneses, Luis de Encío y Juan de Páez, que vivieron en la ciudad de Guadalajara durante el siglo XVII. Ambos llegaron a tener una presencia social poco común, sobre todo el segundo de ellos, que llegó a codearse con los principales mercaderes, terratenientes y miembros del alto clero de la ciudad. Sus vidas son analizadas en el apasionante libro de Melba Falck y Héctor Palacios (2009). 
¿Cómo funcionaba el comercio de la ruta transpacífica? Casi desde el principio se organizó un reparto a partir de boletas de permiso para poder transportar mercancías desde Manila a Acapulco. Las boletas eran certificados de propiedad de cada pieza de carga. La cantidad de mercancía que cada comerciante podía embarcar dependía del número de boletas que tenía, y que no podían cederse ni venderse. Las mercancías se empacaban en balas o fardos, cada uno sellado o marcado con los nombres o las iniciales de los remitentes. ${ }^{22}$ Tras unos primeros años de mayor libertad y de descontrol, en 1593 se promulgaron las primeras restricciones para el comercio transpacífico. A partir de ese año, dicho comercio se convirtió en monopolio estatal, regulado por el Estado, y se estipuló que todo registro debía hacerse ante oficiales reales (Sales, 2000, p. 23).

En esa primera regulación de 1593 se limitó, igualmente, el valor máximo de las mercancías y de la plata que se transportaba entre ambos lados del océano. Los productos transportados desde Manila a Acapulco no podían exceder de 250 mil pesos en su valor, y en su retorno de Acapulco a Manila se podían llevar, como máximo, 500 mil pesos en plata. En 1702 se aumentó el permiso a 300 mil pesos y a 600 mil en el retorno, y en 1734 a medio millón de pesos en mercancías a Acapulco y a un millón para el retorno (Yuste, 1984, pp. 14-16).

Otro aspecto que se reguló fue el número de barcos que podían viajar. Al principio no había control, pero a partir de 1593, lo común fue que zarparan dos galeones juntos de Manila a Acapulco. Sin embargo, los comerciantes preferían el uso de un solo barco, porque tenían la sensación de que los riesgos se minimizaban de esta manera. A partir de 1650, la navegación se realizó comúnmente en un solo barco, medida que fue legitimada por la Corona en 1702, al ordenar que hubiera un solo navío de 500 toneladas para el trayecto (Yuste, 2012, pp. 201-202).

Otra cuestión que se reguló casi desde el principio, y que influiría enormemente en toda la dinámica económica de la América española, fue el ámbito geográfico del comercio transpacífico. En una Real Cédula de 1579 se permitía llevar mercancías asiáticas a Nueva España, Guatemala y Perú. Ese momento histórico coincidía con el auge del virreinato sudamericano (hacia 1575, las minas peruanas producían más plata que las novohispanas). En esos primeros

22. Una de las investigadoras que más ha estudiado el funcionamiento de la ruta del Galeón de Manila desde el punto de vista económico es Carmen Yuste (1984). 
años de la ruta transpacífica, los galeones de Manila podían llegar hasta el puerto de El Callao, en Perú.

Sin embargo, en 1591 se prohibió el comercio directo de Asia con el virreinato peruano y, dos años después, con Guatemala. El tráfico mercantil con Filipinas se limitó, así, única y exclusivamente al puerto de Acapulco (Valdés, 2012, p. 181). En un primer momento se permitió que los comerciantes peruanos, o peruleros, comerciaran directamente con la Nueva España y se beneficiaran del comercio asiático. Sin embargo, a partir de 1639, se prohibió la navegación peruana a Acapulco, lo que suponía que el tráfico transpacífico se debía realizar única y exclusivamente entre las Filipinas y la Nueva España (Yuste, 2012, p. 212). A pesar de todas las regulaciones, los peruleros siguieron haciendo llegar a Lima y a toda Sudamérica los productos asiáticos, muchas veces por cauces no oficiales, es decir, mediante el contrabando. ${ }^{23}$

\section{Las ganancias de la ruta transpacífica}

¿Quién controlaba el comercio del galeón? Casi desde el principio, el monopolio real del comercio transpacífico estuvo en manos de los habitantes de Manila, no de los novohispanos. Una Real Cédula del 10 de febrero de 1635 ordenaba que el comercio transpacífico sólo pudiera ser ejercido por los que hubieran residido en Manila por más de ocho años (Valdés, 2012, p. 181). Sin embargo, esa disposición legal no impidió que, en realidad, fueran los comerciantes de la Ciudad de México quienes tuvieran el control del comercio transpacífico. El Consulado de la capital virreinal, que aglutinaba a los mercaderes de la ciudad, ejerció un enorme poder para llevar a cabo sus intereses. Se estableció como grupo de presión que llegó a obtener grandes privilegios por parte de las autoridades novohispanas. ${ }^{24}$ Normalmente, los grandes comerciantes de la Ciudad de México tenían corresponsales viviendo en Manila, que eran los que firmaban las boletas, aunque finalmente el control estaba en la capital virreinal. Además, conforme avanzaba el tiempo, el comercio de la ruta entre Manila y Acapulco iba siendo controlado por un número cada vez menor de personas. Por ejemplo, el galeón San Martín, en 1586, tuvo 194 cargadores

23. Dos libros recientes que estudian la dinámica del comercio transpacífico y su influencia en todo el continente americano, desde México hasta Argentina, son los de Mariano Bonialian (2012, 2014).

24. Una obra que ha estudiado en profundidad el papel de los comerciantes novohispanos en el comercio transpacífico, particularmente en el siglo XVIII y parte del XIX, es la de Yuste (2007). 
distintos, mientras que dos siglos después, en 1786, la carga del galeón San Andrés pertenecía sólo a 28 personas diferentes (De Miguel, 2008, p. 127).

El comercio transpacífico podía dar más ganancias que el del Atlántico. Pero, al mismo tiempo, era también una empresa más aventurada. Entre 1580 y 1630, la mayor parte de los viajes no se realizó de manera totalmente exitosa. Sin embargo, a partir de la mitad del siglo XVII, la ruta adquirió estabilidad y seguridad, hasta llegar a lo que Carmen Yuste denomina "dinamismo rutinario" (2012, p. 204). Durante la segunda mitad del siglo XVII y la primera del XVIII, es decir, durante la época central de funcionamiento de la ruta transpacífica, hubo gran regularidad en las salidas y llegadas de los barcos a los puertos. El galeón partía de Manila en junio o julio, con el monzón de verano, y llegaba a Acapulco en noviembre o diciembre. Entre enero y febrero se descargaban las mercancías en Acapulco. El barco salía de Acapulco hacia marzo o, como mucho, abril, y llegaba a Manila entre junio y julio, justo cuando estaba saliendo otro galeón con dirección a la Nueva España (Yuste, 2012, p. 202).

Al llegar el galeón a la Nueva España, se llevaba a cabo la feria de Acapulco (normalmente en enero o febrero de cada año). La feria duraba entre 20 días y dos meses y allí se vendían las mercancías asiáticas. El puerto adquiría entonces una animación extraordinaria. Los productos que sobraban se enviaban a la Ciudad de México, llevados por los arrieros, siempre por caminos oficiales. ${ }^{25}$ Allí se vendían en el Parián, mercado cuyo nombre evocaba al de Manila. Algunas de las mercancías asiáticas permanecían en la Ciudad de México, pero otras iban a otros lugares de la Nueva España e, incluso, a España por Veracruz, o también al Perú por cauces no oficiales.

\section{El final del Galeón de Manila}

Hubo varias circunstancias que llevaron al declive y la desaparición de la ruta del Galeón de Manila. Con las reformas borbónicas de Carlos III, en 1785 se creó la Real Compañía de Filipinas. Esto posibilitó la llegada de barcos desde España directamente al archipiélago filipino, por la ruta del Cabo de Buena Esperanza, terminando así dos siglos de monopolio novohispano para el

25. Los arrieros tuvieron una gran influencia en el comercio de las mercancías asiáticas en la Nueva España. Slack (2012, pp. 102-105) estudia como ejemplo el caso de un arriero proveniente de Pampanga (Filipinas), Domingo de Villalobos, que transportaba mercancías asiáticas de Acapulco a las ciudades de México, Colima y Guadalajara. 
comercio de mercancías asiáticas en el mundo hispano. ${ }^{26} \mathrm{Al}$ mismo tiempo, Acapulco perdió su exclusividad como único puerto de altura del Pacífico novohispano. En 1780 se fundó el departamento marítimo de San Blas, desde donde partirían las expediciones para crear asentamientos permanentes en la Alta California. Este nuevo puerto se convirtió en un lugar de construcción y reparación de barcos, y los galeones filipinos empezaron a repararse allí. Finalmente, empezó una relación más fluida entre San Blas y las Filipinas, en detrimento de Acapulco (Pinzón, 2012, pp. 258-265).

La guerra de independencia mexicana terminó con la ruta transoceánica. En marzo de 1815 partió de Acapulco hacia Manila el último galeón, con el simbólico nombre de Magallanes.

\section{Conclusión}

En el presente artículo se ha pretendido ofrecer una visión panorámica de la historia del Galeón de Manila, un estado de la cuestión de los varios aspectos relacionados con esta vía tan importante de comunicación entre ambos lados del Pacífico, y que constituye un capítulo esencial para entender la historia y las relaciones internacionales del virreinato novohispano. En mis conversaciones con mexicanos y mexicanas, incluidos universitarios, siempre me ha sorprendido lo poco que se conoce a escala popular esta parte de la historia de México. Aunque ha habido diversas publicaciones en las últimas décadas sobre la historia y las implicaciones del Galeón de Manila o Nao de China, creo que todavía falta mucho por hacer, tanto en el ámbito de la investigación especializada (en particular en cuanto a la influencia de esta ruta transpacífica en el país que es hoy México), como en el ámbito de conocimiento general en la población mexicana. Es con ese ánimo que he escrito este artículo.

A través de las páginas precedentes se ha visto cómo surgió la ruta del Galeón, y cómo desde el principio tuvo enorme influencia en la historia económica, no sólo de Filipinas, sino también de China, de México y de otros países. A pesar de las regulaciones impuestas desde la metrópoli, el comercio del Galeón no dejó de crecer. Pero más allá de la obvia influencia de las mercancías que se transportaban entre Acapulco y Manila en la economía local y mundial, todavía es más impresionante y menos conocida la circulación

26. Un estudio muy completo sobre la Real Compañía de Filipinas es el ya clásico libro de María Lourdes Díaz-Trechuelo (1965). 
de textos, de ideas, tanto religiosas como culturales y científicas. Se han analizado varios ejemplos de textos acerca de China escritos en Filipinas que dieron a conocer la realidad asiática en América y en Europa, y se ha visto que, incluso controversias religiosas donde el punto central era la religiosidad de los chinos, se llevaron a cabo no sólo en países europeos, sino también en la Nueva España, lo que hizo de esta ruta una de las primeras que dio lugar a un ambiente intelectual y religioso "global", en el más amplio sentido de la palabra. Por último, la circulación de personas, transportando sus lenguas, sus costumbres, su cosmovisión, transformó de manera determinante la realidad de Filipinas y de México. En definitiva, sin conocer la ruta del Galeón de Manila, no se puede entender buena parte del mundo de hoy.

\section{Referencias}

Aduarte, D. (1640/1962). Historia de la Provincia del Santo Rosario de la Orden de Predicadores en Filipinas, Japón y China. Manila, Filipinas, 1640. [Edición moderna: Madrid, España: Consejo Superior de Investigaciones Científicas, 1962].

Alonso, L. (2009). El costo del imperio asiático. La formación colonial de las islas Filipinas bajo dominio español, 1565-1800. México, D.F., México: Instituto Mora, Universidad de la Coruña.

Archivo General de Indias (AGI). PAtronato, 24, "Carta de Legazpi al virrey de Nueva España, Panay, 25 de julio de 1570”. Recuperado de http://www. upf.edu/asia/projectes/che/s16/lega1570.htm

Archivo General de Indias (AGI). PATRONATO, 24, "Carta de Legazpi al virrey, 11 de agosto de 1572”. Recuperado de https://www.upf.edu/asia/projectes/ che/s16/lega1572.htm

Archivo Histórico Nacional de España (AHN). Doc. Ind., Secc. Div., núm. 219, "Carta del Virrey de México a Felipe II, México, 5 de diciembre de 1573". Recuperado de https://www.upf.edu/asia/projectes/che/s16/virr1573.htm

Balbuena, B. (1604/2014). Grandeza mexicana. Ciudad de México, Nueva España, 1604 [Edición moderna: México, D.F., México: Academia Mexicana de la Lengua, Colección Clásicos de la Lengua Española, 2014].

Barrón, C. (Coord.). (2012). Urdaneta novohispano: la inserción del mundo hispano en Asia. México, D.F., México: Universidad Iberoamericana.

Bernabéu, S. (1992). El Pacífico Ilustrado: Del lago español a las grandes expediciones (Colección Mar y América, 4). Madrid, España: Mapfre. 
Bernabéu, S. (Coord.). (2013). La Nao de China, 1565-1815: navegación, comercio e intercambios culturales. Sevilla, España: Universidad de Sevilla.

Bernabéu, S. \& Martínez Shaw, C. (Eds.). (2013). Un océano de seda y plata: el universo económico del Galeón de Manila. Sevilla, España: CSIC.

Bernard, H. (1933). Aux portes de la Chine. Les missionnaires du Seizième Siècle. 1514-1588. Tianjin, China: Hautes Études.

Bonialian, M. A. (2012). El Pacífico hispanoamericano: política y comercio asiático en el imperio español, 1680-1784: la centralidad de lo marginal. México, D.F., México: El Colegio de México.

Bonialian, M.A. (2014). China en la América colonial: bienes, mercados, comercio y cultura del consumo desde México hasta Buenos Aires. México, D.F., México: Instituto Mora, Biblos.

Botton, F. (2000). China, su historia y cultura hasta 1800 ( $2^{\mathrm{a}}$ ed.). México, D.F., México: El Colegio de México.

Cabrero, L. (2009). Alegría, tristeza y ansiedad en la travesía del Galeón de Manila por el Océano Pacífico. En S. Truchuelo (Ed.)., Andrés de Urdaneta: un hombre moderno (pp. 563-586). Ordizia, España: Ayuntamiento de Ordizia.

Cervera, J. A. (2013). Tras el sueño de China. Agustinos y dominicos en Asia Oriental a finales del siglo XVI. Madrid, España: Plaza y Valdés.

Cervera, J. A. (2015). Cartas del Parián. Los chinos de Manila a finales del siglo XVI a través de los ojos de Juan Cobo y Domingo de Salazar. México, D.F., México: Palabra de Clío.

Cervera, J. A. \& Martínez, R. (2018). Puebla de los Ángeles, entre China y Europa. Palafox en las controversias de los ritos chinos. Historia Mexicana, 68(269), 245-284. doi: http://dx.doi.org/10.24201/hm.v68i1.3642

Chaunu, P. (1974). Las Filipinas y el Pacífico de los Ibéricos. Siglos XVI-XVII-XVIII. (Estadísticas y Tablas). México, D.F., México: Instituto Mexicano de Comercio Exterior.

Chong, J. L. (2013). Los sangleyes chinos en el comercio novohispano (1550-1800) (Tesis doctoral). Universidad Nacional Autónoma de México, México, D.F., México.

De Miguel, J. R. (2008). Urdaneta y su tiempo. Ordizia, España: Ayuntamiento de Ordizia.

Del Castillo, A. (2012). Timor: el comercio del sándalo en la ruta de las especias (siglos XVI al XVIII). En C. Barrón (Coord.), Urdaneta novohispano: la inserción del mundo hispano en Asia (pp. 117-143). México, D.F., México: Universidad Iberoamericana. 
Díaz-Trechuelo, M. L. (1965). La Real Compañía de Filipinas. Sevilla, España: Esc. Gráf. Salesiana.

Falck, M. \& Palacios, H. (2009). El japonés que conquistó Guadalajara. La historia de Juan de Páez en la Guadalajara del siglo XVII. Guadalajara, México: Universidad de Guadalajara, Biblioteca Pública del Estado de Jalisco Juan José Arreola.

Folch, D. (2008). Biografía de Fray Martín de Rada. Huarte de San Juan. Geografía e Historia, 15, 33-63.

García de los Arcos, M. F. (1996). Forzados y reclutas: los criollos novohispanos en Asia, 1756-1808. México D.F., México: Potrerillos.

Gil, J. (1989) Mitos y Utopías del Descubrimiento. 2. El Pacífico. Madrid, España: Alianza Editorial.

Gutiérrez, L. (1992). Historia de la Iglesia en Filipinas (Colección Iglesia Católica en el Nuevo Mundo, 4). Madrid, España: Mapfre.

Hidalgo, P. (1995). Los primeros de Filipinas. Crónicas de la conquista del archipiélago de San Lázaro. Madrid, España: Miraguano y Polifemo.

Legarda, B. (2009). El comercio de Filipinas con el Sudeste asiático durante la época del Galeón de Manila. En S. Truchuelo (Ed.)., Andrés de Urdaneta: un hombre moderno (pp. 605-620). Ordizia, España: Ayuntamiento de Ordizia.

Minamiki, G. (1985). The Chinese Rites Controversy from Its Beginning to Modern Times. Chicago, Estados Unidos: Loyola University Press.

Moffett, S. H. (2005). A History of Christianity in Asia (Vol. II, 1500-1900). Nueva York, Estados Unidos: Orbis.

Molina, A. M. (1992). América en Filipinas (Colección Realidades Americanas, 3). Madrid, España: Mapfre.

Morales, F. (2008). De la utopía a la locura. El Asia en la mente de los franciscanos de la Nueva España: del siglo XVI al XIX. En E. Corsi (Coord.). Órdenes religiosas entre América y Asia: ideas para una historia misionera de los espacios coloniales (pp. 57-83). México, D.F., México: El Colegio de México.

Morga, A. (1609/1890). Sucesos de las Islas Filipinas. México, Nueva España, 1609 [Edición moderna: París, Francia: Librería de Garnier Hermanos, 1890].

Ollé, M. (2002). La empresa de China. De la Armada Invencible al Galeón de Manila. Barcelona, España: Acantilado.

Ollé, M. (2006). La formación del Parián de Manila: la construcción de un equilibrio inestable. En P. San Ginés (Ed.)., La investigación sobre Asia Pacífico en España (pp. 27-49). Granada, España: Universidad de Granada. 
Oropeza, D. (2011). La esclavitud asiática en el virreinato de la Nueva España, 1565-1673. Historia Mexicana, 61(241), 5-57.

Pinzón, G. (2012). La inserción de San Blas en las navegaciones transpacíficas (1768-1789). En C. Barrón (Coord.). Urdaneta novohispano: la inserción del mundo hispano en Asia (pp. 253-279). México, D.F., México: Universidad Iberoamericana.

Remesal, A. (1619). Historia de la Provincia de S. Vicente de Chiapa y Guatemala de la Orden de Ntro. Glorioso Padre Sancto Domingo. Madrid, España: Francisco de Angulo.

Retana, W. E. (1897). Archivo del Bibliófilo Filipino. Recopilación de documentos históricos, científicos, literarios y políticos y estudios bibliográficos (Tomo 3). Madrid, España: Imprenta de la Viuda de M. Minuesa de los Ríos.

Rodríguez, I. (1978). Historia de la Provincia Agustiniana del Smo. Nombre de Jesús de Filipinas (Vols. 13 y 14). Manila, Filipinas: Arnoldus Press.

Rumeu de Armas, A. (1992). El Tratado de Tordesillas (Colección América 92, 12). Madrid, España: Mapfre.

Sales, O. (2000). El movimiento portuario de Acapulco. El protagonismo de Nueva España en la relación con Filipinas, 1587-1648. México, D.F., México: Plaza y Valdés.

Sánchez, J.-N. (2009). Tiempos Malucos. España y sus Islas de las Especias, 1565-1663. En S. Truchuelo (Ed.)., Andrés de Urdaneta: un hombre moderno (pp. 621-650). Ordizia, España: Ayuntamiento de Ordizia.

Sánchez, V. \& Fuertes, C. (1979). España en Extremo Oriente. Filipinas, China, Japón: presencia franciscana, 1578-1978. (Colección Publicaciones Archivo Ibero-Americano). Madrid, España: Cisneros.

Seijas, T. (2014). Asian Slaves in Colonial Mexico. From Chinos to Indians. Cambridge, Reino Unido: Cambridge University Press.

Slack, E. R. (2012). Orientalizing New Spain: Perspectives on Asian Influence in Colonial Mexico. México y la Cuenca del Pacífico, 15(43), 97-127. doi: https://doi.org/10.32870/mycp.v15i43.380

Sola, D. (2016). Juan González de Mendoza y la Historia del Gran Reino de la China: la construcción del relato sinológico desde la Europa del Quinientos. Revista Estudios, 32, 1-23.

Truchuelo, S. (Ed.). (2009). Andrés de Urdaneta: un hombre moderno. Ordizia, España: Ayuntamiento de Ordizia.

Valdés, V. (1987). De las minas al mar: Historia de la plata mexicana en Asia 1565-1834. México, D.F., México: Fondo de Cultura Económica. 
Valdés, V. (2012). La importancia de la plata novohispana en Asia. En C. Barrón (Coord.). Urdaneta novohispano: la inserción del mundo hispano en Asia (pp. 179-197). México, D.F., México: Universidad Iberoamericana.

Vega, M. J. (Ed.). (2009). Viajes y crónicas de China en los Siglos de Oro. Córdoba, España: Almuzara.

Villarroel, F. (Ed.). (1986). Pien Cheng-Chiao Chen-Ch'uan Shih Lu. Apología de la Verdadera Religión. Manila, Filipinas: Ust Press. [Reproducción facsímil del original chino de Juan Cobo, Manila, 1593, con traducción al español $\mathrm{y}$ al inglés].

Yuste, C. (1984). El comercio de la Nueva España con Filipinas. 1590-1785. México, D.F., México: Instituto Nacional de Antropología e Historia.

Yuste, C. (2007). Emporios transpacíficos. Comerciantes mexicanos en Manila, 1710-1815. México, D.F., México: Universidad Nacional Autónoma de México.

Yuste, C. (2012). El dinamismo rutinario de la carrera transpacífica. En C. Barrón (Coord.). Urdaneta novohispano: la inserción del mundo hispano en Asia (pp. 199-222). México, D.F., México: Universidad Iberoamericana.

Zhang, K. (2003). Historia de las Relaciones Sino-Españolas. Beijing, China: Elephant Press. 